\title{
Knowledge, attitude and practice towards needle stick injury among health care workers in a tertiary Sudanese hospital
}

\author{
Article By Mohamed D. Dafaalla, Asgad suliman ${ }^{1}$, Abdelmoneim E.M. Kheir ${ }^{2}$, Mahil \\ Abdalla $^{1}$, Ahmed Hashim ${ }^{1}$, Najla Mohammed ${ }^{1}$, Mehera Mirghani ${ }^{1}$, Mohammed \\ Nimir $^{1}$, Manal Haroon ${ }^{1}$, Hani ElHag ${ }^{1}$, Elmubarak Shadad ${ }^{1}$, Mohamed Dafaalla ${ }^{3}$, Ihab \\ Abdalrahman ${ }^{4}$ \\ ${ }^{1}$ Fellow of Soba Centre for Audit and Research (SCAR), Khartoum, Sudan \\ ${ }^{2}$ Associate professor Department of pediatrics, Faculty of medicine, University of \\ Khartoum and Soba university hospital \\ ${ }^{3}$ MBBS, Diploma of statistics, executive manager of Soba Centre for Audit and \\ Research, Soba university hospital, Khartoum, Sudan \\ ${ }^{4}$ Associate professor of medicine, Faculty of medicine, University of Khartoum and \\ Soba university hospital Khartoum, Sudan \\ ${ }^{5}$ University of Khartoum \\ E-mail: mdafaallah200@gmail.com
}

\begin{abstract}
Introduction: Percutaneous injuries, caused by needle sticks and other sharps, are a serious concern for all health care workers (HCWs) and pose a significant risk of occupational transmission of blood borne pathogen. Two million injuries are believed to occur each year among HCWs. Methodology: The study group consisted of 249 HCWs of various categories of a tertiary care hospital in Khartoum, Sudan. Data collection was carried out using a standardized questionnaire. To measure knowledge, attitude and practices on needle stick injuries. Results: $70 \%$ of respondents were females and around $47 \%$ of participants were nurses Half of participants attended a biosafety course, and around $90 \%$ of them followed what they was trained on in all or most of times. Most of respondents graded their knowledge about as good and the main source of knowledge was the university curriculum. In our study 46\% had NSI with a mean of 6.1 injuries/year of 6.14 most of them were among nurses $40 \%$. Almost thirty percent didn't hear about the term post exposure prophylaxis more than $90 \%$ knew that HIV, HBV, and HIV can be transmitted through NSI. More than $83 \%$ of respondents were worried about NSI. Regarding the most recent NSI, Most of injuries occurred in the ward followed by emergency room, lab, and theatre. In half of cases the culprit was the victim himself during usage of syringe. The most common procedure associated with NSI was blood sampling. The frequent action was to wash the injury site using antiseptic solution. Almost two thirds of respondents who had NSI didn't report it. Around $4.3 \%$ had NSI of HIV patient yet, the majority of them did not receive any medication. Out the 7 participants who had a NSI from a HBV positive patient, 5 were fully vaccinated all of which didn't check their vaccination status. Moreover, none of the 5 participants received PEP. Conclusion and recommendation: prevalence of NSI was relatively low but there were many deficient area such as checking immune status of $\mathrm{HBV}$, knowledge about importance and methods of PEP, role of wearing gloves during handling needles, and procedure of reporting injuries.

$H C W=$ health care worker $N S I=$ needle stick injuries $P E P=$ post exposure prophylaxis
\end{abstract}

Keywords: KAP, needle stick injury, Soba University hospital, Sudan

\section{Introduction}

It is estimated that there are 35 million healthcare workers (HCWs) worldwide representing $12 \%$ of the working population. Two million injuries are believed to occur each year among HCWs.[1]Approximately 3 million health care workers (HCWs) experience 
South American Journal of Clinical Research

Volume 3, Issue 1, 2016

percutaneous exposure to blood borne viruses (BBVs) each year. This results in an estimated 16,000 hepatitis C, 66,000 hepatitis B, and 200 to 5000 human immunodeficiency virus (HIV) infections annually. [2]

Percutaneous injuries, caused by needle sticks and other sharps, are a serious concern for all health care workers (HCWs) and pose a significant risk of occupational transmission of blood borne pathogen. Although sharp instruments injuries are preventable, a minor injury can carry the risk of transfer of over twenty pathogens of which the most serious are Hepatitis B virus (HBV), Hepatitis C virus (HCV) and Human Immunodeficiency virus (HIV).[3, 4]

Needle stick injuries are defined as wounds that are caused by sharp objects like hypodermic needles, fluid collection needles and IV cannel as which are attributed due to improper handling or manipulation of needles in different activities such as obtaining or transferring sample specimens, recapping activities and failure to dispose needles in puncture proof containers. [3]

Those injuries and blood-borne infections can be prevented by applying various strategies such as immunization for hepatitis B virus, post exposure prophylaxis and procedures to prevent percutaneous injuries.[5]

It is estimated that worldwide contaminated injection cause 8-16 million hepatitis B virus infection, around 2.4 to 4.5 million hepatitis $C$ virus infection and about 80,000 to 160,000 HIV infections.[6] In 2000-2030, WHO estimate that 16000 HCV infections attributable to sharps injuries will result in 142 (51-749) early deaths. Similarly, the $66000 \mathrm{HBV}$ infections will lead to 261 (86-923) early deaths, and about 736 (129-3578) healthcare workers will die prematurely from 1000 HIV infections.[5]

The incidence of NSI is considerably higher than current estimates, due to gross underreporting (often less than 50\%). In USA 6,00,000 to 10,00,000 receive NSI from conventional needles and sharps every year, while in UK it is 1,00,000 HCWs/year. In India, authentic data on NSI are scarce. It is known that around 3-6 billion injections are given per year, of which 2/3rd injections are unsafe (62.9\%) moreover in a study done at dental school in Sudan there is (69.6\%) students reported being exposed to a sharp instruments injury. [1, 3]

Infection by the human immunodeficiency virus (HIV) and hepatitis B virus (HBV) pose great health problems worldwide particularly in the developing countries. The risk of occupational BBI for HCWs in low and middle income countries is high due to crowded hospitals, high patient load per HCW, limited knowledge of risks, inadequate personal protective equipment (PPE), lack of sharps containers, limited knowledge and utilization of Post Exposure Prophylaxis (PEP), low adherence to Universal Precautions (UP), high prevalence of patients with BBI and low hepatitis B vaccination coverage among HCWs.24As 2 million cases of HCV and 21 million of HBV infections are due to unsafe therapeutic injections,5poor adherence to UP puts both patients and HCWs at risk of BBI.[2, 7-9]

Preventing NSI is an essential part of any blood borne pathogen prevention program in the work place. With regard to prevention, when exposures occur, the risk of infection can be significantly reduced by following protocols for PEP. Guidelines have been issued for the management of HCWs who have had occupational exposure to blood borne pathogens. This includes urgent valuation of the source and exposed person's status along with the timely administration of hepatitis B immune globulin (HBIG), hepatitis B vaccine and/or HIV PEP where applicable. For

HCV, testing should be performed to determine if infection develops. [7, 10-13]

The present study addresses the important issue of NSI and aims at determining the occurrence of NSI among different categories of HCWs, the various factors responsible, the circumstances under which these occur and explores the availability and possibilities of measures to prevent these through improvement in knowledge, attitude and practice.

\section{Methodology}

A descriptive cross sectional hospital based study was carried out among HCW at soba university hospital at December 2015. This hospital is a tertiary care referral hospital was 
established in 1975 in Khartoum, Sudan. Total of 249 nurses, doctors and lab technician were surveyed using stratified multistage sampling technique. Data collection was carried out using a standardized questionnaire. Which was created based on review of the literature, a researcher was present during the survey administration to answer queries raised by respondents.

The study variables included socio demographic data Variables : ( age ,gender ,specialty, duration of work, HBV immunization status, know the universal and local precaution guideline, use of gloves, the presences of occupation health service in the hospital ,knowledge variables: (infection can transmitted by blood, immediate action after NSI,PEP), Attitude variables:(their worries concerning NSI, reporting the accident ,patient safety, is it preventable, their attitude after NSI) ,practice variables were:(immediate action, report the accident, characteristic of the event, NSI from high risk patient)

The respondents were given a briefing on the aims of the study, and verbal consent was taken from each candidate, Clearance of study protocol was obtained from the hospital ethics committee before the start of the study.

Data analysis was carried out with statistical package for scientific solutions (SPSS) version 22.0

\section{RESULTS}

$70 \%$ of respondents were females and around $47 \%$ of participants were nurses out of 249 participants. Half of participants attended a biosafety course, and around $90 \%$ of them followed what they was trained on in all or most of times. Most of respondents graded their knowledge about as good and the main source of knowledge was the university curriculum. In our study $46 \%$ had NSI with a mean of 6.1 injuries/year of 6.14 most of them were among nurses $40 \%$. Table (1) below demonstrates the demographic data of the respondents. Table (2) illustrates the knowledge and attitudes towards NSI, whereas Table (3) presents the practice of medical personnel towards the most recent NSI.

Table 1. demographic data.

\begin{tabular}{|c|c|c|c|}
\hline & & N\% & Mean \\
\hline \multirow[t]{2}{*}{ Gender } & Male & $29.4 \%$ & \\
\hline & female & $70.6 \%$ & \\
\hline \multirow[t]{6}{*}{ Specialty } & nurse & $47.4 \%$ & \\
\hline & lab technician & $16.3 \%$ & \\
\hline & medical officer & $4.9 \%$ & \\
\hline & registrar & $12.8 \%$ & \\
\hline & house officer/under training & $16.0 \%$ & \\
\hline & consultant & $2.6 \%$ & \\
\hline \multirow{2}{*}{$\begin{array}{l}\text { know the last Universal } \\
\text { Precaution Guidelines of the } \\
\text { needle stick injuries management }\end{array}$} & yes & $54.1 \%$ & \\
\hline & no & $45.9 \%$ & \\
\hline \multirow[t]{2}{*}{ attend a biosafety course } & yes & $49.1 \%$ & \\
\hline & no & $50.9 \%$ & \\
\hline \multirow{5}{*}{$\begin{array}{l}\text { follow what you had been trained } \\
\text { in the biosafety course }\end{array}$} & always & $54.2 \%$ & \\
\hline & most of the time & $36.9 \%$ & \\
\hline & some time & $3.9 \%$ & \\
\hline & rarely & $1.7 \%$ & \\
\hline & never & $3.4 \%$ & \\
\hline \multirow{4}{*}{$\begin{array}{l}\text { your knowledge about the local } \\
\text { policy in the hospital about needle } \\
\text { stick injuries }\end{array}$} & excellent & $18.2 \%$ & \\
\hline & very good & $29.1 \%$ & \\
\hline & Good & $36.8 \%$ & \\
\hline & Bad & $15.9 \%$ & \\
\hline
\end{tabular}


South American Journal of Clinical Research

Volume 3, Issue 1, 2016

\begin{tabular}{|c|c|c|c|}
\hline \multirow{5}{*}{$\begin{array}{l}\text { main source of information about } \\
\text { needle stick injuries }\end{array}$} & collage curriculum & $41.7 \%$ & \\
\hline & hospital & $31.3 \%$ & \\
\hline & media & $8.6 \%$ & \\
\hline & training course & $11.9 \%$ & \\
\hline & others & $6.5 \%$ & \\
\hline \multirow[t]{3}{*}{ hepatitis B virus vaccination } & fully vaccinated & $65.4 \%$ & \\
\hline & $\begin{array}{l}\text { did not complete the } \\
\text { vaccination }\end{array}$ & $18.0 \%$ & \\
\hline & not vaccinated & $16.6 \%$ & \\
\hline \multirow[t]{3}{*}{ Anti HBs antibodies level } & $\begin{array}{l}\text { HBsAb more than or equal } 10 \\
\mathrm{mIU} / \mathrm{mL}\end{array}$ & $8.2 \%$ & \\
\hline & HBsAb less than $10 \mathrm{mIU} / \mathrm{mL}$ & $5.3 \%$ & \\
\hline & not checked & $86.5 \%$ & \\
\hline \multirow[t]{5}{*}{ use gloves when deal with needles } & always & $63.6 \%$ & \\
\hline & most of the time & $25.2 \%$ & \\
\hline & some time & $8.2 \%$ & \\
\hline & rarely & $2.1 \%$ & \\
\hline & never & $0.9 \%$ & \\
\hline \multicolumn{2}{|l|}{ Age } & & 31.02 \\
\hline \multicolumn{2}{|c|}{$\begin{array}{l}\text { Duration of time since you start using needles in the medical field } \\
\text { (in years) }\end{array}$} & & 8.53 \\
\hline \multicolumn{2}{|l|}{ use needles per week on average } & & 19.45 \\
\hline \multicolumn{2}{|c|}{ frequency of contaminated needle stick injury per year } & & 6.14 \\
\hline
\end{tabular}

Table 2. knowledge and attitudes towards NSI.

\begin{tabular}{|c|c|c|}
\hline & & $\mathrm{N} \%$ \\
\hline \multirow[t]{2}{*}{ heard about the term post exposure prophylaxis } & Yes & $70.7 \%$ \\
\hline & No & $29.3 \%$ \\
\hline \multirow{5}{*}{$\begin{array}{l}\text { main source of information about post exposure } \\
\text { prophylaxis }\end{array}$} & collage curriculum & $36.5 \%$ \\
\hline & hospital & $35.2 \%$ \\
\hline & media & $9.2 \%$ \\
\hline & training course & $11.2 \%$ \\
\hline & others & $7.9 \%$ \\
\hline \multirow{3}{*}{$\begin{array}{l}\text { is there occupational health services in the } \\
\text { hospital }\end{array}$} & yes & $67.9 \%$ \\
\hline & I do not know & $21.9 \%$ \\
\hline & No & $10.2 \%$ \\
\hline \multirow{3}{*}{$\begin{array}{l}\text { Hepatitis B virus infection can be transmitted by } \\
\text { blood }\end{array}$} & yes & $95.9 \%$ \\
\hline & I do not know & $0.9 \%$ \\
\hline & No & $3.2 \%$ \\
\hline \multirow{3}{*}{$\begin{array}{l}\text { Hepatitis C virus infection can be transmitted by } \\
\text { blood }\end{array}$} & Yes & $90.7 \%$ \\
\hline & I do not know & $2.7 \%$ \\
\hline & No & $6.6 \%$ \\
\hline \multirow{3}{*}{$\begin{array}{l}\text { HIV } \backslash A I D S \text { infection can be transmitted by } \\
\text { blood? }\end{array}$} & Yes & $99.1 \%$ \\
\hline & I do not know & $0.3 \%$ \\
\hline & No & $0.6 \%$ \\
\hline \multirow{3}{*}{$\begin{array}{l}\text { If you have a needle stick your immediate action } \\
\text { will be to wash your hand with soap and water? }\end{array}$} & Yes & $77.8 \%$ \\
\hline & I do not know & $3.0 \%$ \\
\hline & No & $19.2 \%$ \\
\hline \multirow{3}{*}{$\begin{array}{l}\text { If you have a needle stick your immediate action } \\
\text { will be to wash your hand with water only? }\end{array}$} & Yes & $16.2 \%$ \\
\hline & I do not know & $2.5 \%$ \\
\hline & No & $81.3 \%$ \\
\hline
\end{tabular}




\begin{tabular}{|c|c|c|}
\hline \multirow{3}{*}{$\begin{array}{l}\text { If you have a needle stick your immediate action } \\
\text { will be to wash your hand with antiseptic } \\
\text { solution? }\end{array}$} & Yes & $89.6 \%$ \\
\hline & I do not know & $2.1 \%$ \\
\hline & No & $8.3 \%$ \\
\hline \multirow{3}{*}{$\begin{array}{l}\text { concerning needle stick injury from HCV } \\
\text { infected patient Direct viral testing with HCV } \\
\text { RNA PCR viral load at } 6 \text { weeks }\end{array}$} & Yes & $48.3 \%$ \\
\hline & I do not know & $43.8 \%$ \\
\hline & No & $7.8 \%$ \\
\hline \multirow{3}{*}{$\begin{array}{l}\text { concerning needle stick injury from HCV } \\
\text { infected patient HCV antibody testing should be } \\
\text { performed at } 4-6 \text { months }\end{array}$} & Yes & $34.8 \%$ \\
\hline & don’t know & $50.3 \%$ \\
\hline & No & $14.8 \%$ \\
\hline \multirow[t]{5}{*}{ I am worry about having needle stick injury } & strongly disagree & $3.6 \%$ \\
\hline & Disagree & $6.0 \%$ \\
\hline & Neutral & $6.9 \%$ \\
\hline & Agree & $41.0 \%$ \\
\hline & strongly agree & $42.5 \%$ \\
\hline \multirow{5}{*}{$\begin{array}{l}\text { because sharps disposal containers are not } \\
\text { changed often enough where I work, I am } \\
\text { concerned about getting a sharps injury }\end{array}$} & strongly disagree & $13.2 \%$ \\
\hline & Disagree & $19.9 \%$ \\
\hline & Neutral & $12.3 \%$ \\
\hline & Agree & $36.5 \%$ \\
\hline & strongly agree & $18.1 \%$ \\
\hline \multirow{5}{*}{$\begin{array}{l}\text { Patient care is more important than the safety of } \\
\text { health care workers. }\end{array}$} & strongly disagree & $42.9 \%$ \\
\hline & Disagree & $26.0 \%$ \\
\hline & Neutral & $13.6 \%$ \\
\hline & Agree & $10.0 \%$ \\
\hline & strongly agree & $7.6 \%$ \\
\hline \multirow{5}{*}{$\begin{array}{l}\text { All sharps injuries at work should be reported } \\
\text { immediately. }\end{array}$} & strongly disagree & $3.0 \%$ \\
\hline & Disagree & $1.8 \%$ \\
\hline & Neutral & $3.0 \%$ \\
\hline & Agree & $41.2 \%$ \\
\hline & strongly agree & $51.0 \%$ \\
\hline \multirow[t]{5}{*}{ I think needle stick injury is preventable? } & strongly disagree & $4.2 \%$ \\
\hline & Disagree & $7.7 \%$ \\
\hline & Neutral & $7.1 \%$ \\
\hline & Agree & $49.1 \%$ \\
\hline & strongly agree & $31.8 \%$ \\
\hline
\end{tabular}

It can be noticed that almost thirty percent didn't hear about the term post exposure prophylaxis up to the time of this study while the college curriculum and hospital were the main source. Almost one of every five didn't recognize the presence of occupational health service in the hospital. More than 90\% knew that HIV, HBV, and HIV can be transmitted through NSI. Almost $80 \%$ chose to use antiseptic solution immediately after NSI compared to only $20 \%$ who chose to use water and soap. One third of respondents believed that post exposure prophylaxis should be used only when the syringe is used on HIV/HBV seropositive patients. Around 43-50\% admitted they didn't know the time of prophylaxis initiation nor investigations that should be done after NSI. More than $83 \%$ of respondents were worried about NSI. However, around $60 \%$ believed that patient care has the priority over protection from NSI. Eighty percent believed that NSI is preventable and $92 \%$ agreed that NSI should be reported immediately.

Regarding the most recent NSI, Most of injuries occurred in the ward followed by emergency room, lab, and theatre. In half of cases the culprit was the victim himself during usage of syringe. The most common procedure associated with NSI was blood sampling. The frequent action was to wash the injury site using antiseptic solution. Almost two thirds of respondents who had NSI didn't report it. This happened mainly because they believed that the injury was minimal or not infectious, or they didn't know how to or where to report. 
South American Journal of Clinical Research

Volume 3, Issue 1, 2016

Around $4.3 \%$ had NSI of HIV patient yet, the majority of them did not receive any medication. Out the 7 participants who had a NSI from a HBV positive patient, 5 were fully vaccinated all of which didn't check their vaccination status. Moreover, none of the 5 participants received PEP.

$97 \%$ of the participants who suffered from a NSI became more cautious, $16 \%$ avoided any procedures involving sharp objects and 26\% didn't change their attitude.

Table 3. practice of medical personnel towards the most recent NSI.

\begin{tabular}{|c|c|c|}
\hline & & $\%$ \\
\hline \multirow[t]{6}{*}{ Where was it } & emergency room & $24.8 \%$ \\
\hline & ward & $31.9 \%$ \\
\hline & theatre & $13.5 \%$ \\
\hline & Lab & $14.9 \%$ \\
\hline & ICU & $9.9 \%$ \\
\hline & outside the hospital & $5.0 \%$ \\
\hline \multirow[t]{4}{*}{ your immediate action was } & washed your hand with soap and water & $32.1 \%$ \\
\hline & washed your hand with water only & $8.8 \%$ \\
\hline & washed your hand with antiseptic & $54.0 \%$ \\
\hline & did nothing & $5.1 \%$ \\
\hline \multirow[t]{3}{*}{ report your injury to your supervisor } & Yes & $34.0 \%$ \\
\hline & No & $60.3 \%$ \\
\hline & NSI was outside the hospital & $5.7 \%$ \\
\hline \multicolumn{3}{|l|}{ Why didn’t you report? } \\
\hline \multirow{2}{*}{$\begin{array}{l}\text { not important (the outcome remaining } \\
\text { unchanged by reporting) }\end{array}$} & Yes & $38.5 \%$ \\
\hline & No & $61.5 \%$ \\
\hline \multirow[t]{2}{*}{ it takes time } & Yes & $31.7 \%$ \\
\hline & no & $68.3 \%$ \\
\hline \multirow[t]{2}{*}{ I thought it would be not infectious } & yes & $52.3 \%$ \\
\hline & no & $47.7 \%$ \\
\hline \multirow[t]{2}{*}{ insignificant exposure } & yes & $53.9 \%$ \\
\hline & no & $46.1 \%$ \\
\hline \multirow[t]{2}{*}{ already immunized for hepatitis B virus } & yes & $51.2 \%$ \\
\hline & no & $48.8 \%$ \\
\hline \multirow[t]{2}{*}{ not know how to report } & yes & $52.8 \%$ \\
\hline & no & $47.2 \%$ \\
\hline \multirow[t]{2}{*}{ Did you follow each step of local policy } & yes & $53.4 \%$ \\
\hline & no & $46.6 \%$ \\
\hline \multirow[t]{4}{*}{ NSI caused by } & myself & $53.7 \%$ \\
\hline & my collage & $11.2 \%$ \\
\hline & manipulation from the patient & $29.1 \%$ \\
\hline & others & $6.0 \%$ \\
\hline \multirow[t]{5}{*}{ the procedure was } & blood sampling & $42.1 \%$ \\
\hline & suturing & $16.5 \%$ \\
\hline & giving injection & $16.5 \%$ \\
\hline & Cannulation & $12.8 \%$ \\
\hline & Others & $12.0 \%$ \\
\hline \multirow[t]{3}{*}{ the NSI happened } & during usage & $50.4 \%$ \\
\hline & during recapping & $31.9 \%$ \\
\hline & during disposal & $17.8 \%$ \\
\hline \multirow[t]{2}{*}{ wear gloves at time of NSI } & Yes & $76.1 \%$ \\
\hline & No & $23.9 \%$ \\
\hline had NSI from HIV positive patient & Yes & $4.3 \%$ \\
\hline
\end{tabular}




\begin{tabular}{|l|l|c|}
\hline & No & $95.7 \%$ \\
\hline \multirow{2}{*}{$\begin{array}{l}\text { did you receive post exposure prophylaxis } \\
\text { after NSI from HIV positive patient }\end{array}$} & $\begin{array}{l}\text { received antiretroviral therapy for } 28 \\
\text { days }\end{array}$ & $17.6 \%$ \\
\cline { 2 - 3 } & $\begin{array}{l}\text { received antiretroviral therapy for less } \\
\text { than 28 days }\end{array}$ & $0.0 \%$ \\
\cline { 2 - 3 } & Did not received any medication & $82.4 \%$ \\
\hline \multirow{2}{*}{$\begin{array}{l}\text { when did you receive post exposure } \\
\text { prophylaxis after NSI from HIV positive } \\
\text { patient }\end{array}$} & within the first 72 hours & $66.7 \%$ \\
\cline { 2 - 3 } & after the first 72 hours & $33.3 \%$ \\
\hline
\end{tabular}

\section{Discussion}

From our study, the prevalence of NSI was $46 \%$. It was lower than that found among doctors in a tertiary health facility in Benin City where the prevalence was found to be 61.87 $\%$. [6]This difference could be explained by Soba's adherence to NSI reducing policies including: provision of safety boxes, education about universal precautions and creation of a positive work environment. The current study also showed that the frequency of NSI is high among nurses (40\%). This is approximate to the study done in a tertiary cardiac center in India, which showed that the frequency of NSI was also high among nurses with rate of 38.4 $\%$. This is most likely due to the relatively more frequent dealing of nurses with sharp instruments. [4]

Approximately $96 \%$ of the study population were aware that HBV is transmitted by blood although only $65 \%$ were fully vaccinated, yet, $86 \%$ of them did not check their Anti HBs antibodies level. Out the 7 participants who had a NSI from a HBV positive patient, 5 were fully vaccinated and all of them didn't check their vaccination status. Moreover, none of the 5 participants received PEP. In a study among dental student the investigator found out that only $76.1 \%$ of students reported being fully vaccinated against hepatitis B. Of the students who were fully vaccinated, $8.3 \%$ knew their immunization status and had reported effective immunity with titer levels above $100 \mathrm{IU} / \mathrm{ml}$.[1]a similar finding was found in a survey in India where only 6 workers (14\%) had been tested for Anti-HBs.[14] In contrast, in a study done in India, $91.5 \%$ out of the total HCWs surveyed were vaccinated against HBV, and the seroconversion status was checked in $76.9 \%$ of them.[4]The reason behind the majority of the sample for not checking their immune status can be due to their false sense of protection against the infection after completion of their vaccination, while others may not know the importance of checking the level of their serum antibodies. The study which was done by Sharma et al explained that as per their hospital policy, antibody titers are not done for all categories of staff on a routine basis.[4]

The study results showed that about $70 \%$ of the sample population have heard about PEP, but only $10 \%$ of them are aware about the importance of PEP and they understand it should not be given for all NSI while it should be given only to seropositive patients. A result obtained from a study done in dentistry college in university of medical science and technology showed about $34.8 \%$ of the dental students were aware of PEP protocol in general while 65.2 were not. This can be explained as a result of the weak coverage of PEP protocols in the curriculum of different health institutions. This can be seen in our study ,as only about $37 \%$ of the sample did know about the PEP from their college curriculum. Another explanation for that is the decreased knowledge of the sample about the local policy of the hospital regarding NSI ,as only $18 \%$ said they have excellent knowledge about it. As seen in the results above majority of health workers in soba hospital do not know PEP protocols. So ,increasing knowledge and awareness of PEP protocols, can be done by making local policies more accessible and improving study curriculums in colleges. As the results showed, the majority of the study sample were not fully aware about the PEP protocol, and the results showed that health institutions curriculums did not contribute effectively in raising the knowledge about the protocol as well as the decreased awareness of their local policy of the hospitals they work in, so a further improvement in these aspects are recommended. [1] 
One of the most important issue in NSI is reporting the accident in the current study. Around 34\% only did that. Participants didn't report their injuries due to different reasons. For example, the participant thought that it is not important (the outcome remaining unchanged by reporting). Others said that it takes time to report, thought that the exposure was nonsignificant, or didn't know how to report their injuries. Some thought that it would not be infectious while others were already immunized. In the same manner, only $21 \%$ reported their injury in a previous study done in India because the health workers were not aware of the importance of PEP. Moreover, in a study done in Khartoum state in Sudan, 21.9\% of students reported their injury the reasons were using of self-care, injury being minor, item being unused and student being busy. The difference in the results can be explained by the fact that our health workers are more aware of the importance of PEP. Other studies showed that the reasons were fear of stigmatization and discrimination, feeling embarrassed, fear of the consequences, the patient was low risk, good local anti-sepsis undertaken at time of injury, heavy clinical schedule, students more concerned with finishing their clinical requirements and not knowing that there is a reporting protocol, negative faculty reaction and negative patient reaction Though the percentage in our study is higher it is still low and so information about PEP can be covered in a workshop given to health workers for example when they are first employed and in the undergraduate curriculum. [1, 14]

In the present study, 31.9\% of NSI were sustained during recapping of needles. This figure is similar to what was reported by Sharma et al (30.7\%) and Ibekwe et al (34\%). In contrast, a KAP study about NSI in Nepal documented a lower figure of $10-25 \%$. The practice of recapping needles has been prohibited since the introduction of the "Universal Precaution Guidelines" in 1985. Thus, the aforementioned high percentages point to the refusal of health care workers to follow the guidelines or the inadequacy of their training. [4, 6, 14]

Among the health care workers studied, 64\% reported using gloves when dealing with needles, less than what was demonstrated by a previous study of the same nature (84\%). Our research and Muralidhar et all's study yielded identical percentages of glove use at the time of NSI (74\%). The malpractice of barehanded dealing with sharp objects can be attributed to lack of awareness, unavailability of gloves or the nuisances that accompany using them, such as: changed sensation, allergic reactions or decreased ability to manipulate. [3]

Almost 5\% of our participants knew that they should wash their hands with soup and water only after NSI moreover 32\% only did that). According to the CDC (center for disease control) report published on 29th June 2001, "Wounds and skin sites that have been in contact with blood or body fluids should be washed with soap and water; mucous membranes should be flushed with water. No evidence exists that using antiseptics for wound care or expressing fluid by squeezing the wound further reduces the risk of blood borne pathogen transmission; however, the use of antiseptics is not contraindicated. The application of caustic agents (e.g., bleach) or the injection of antiseptics or disinfectants into the wound is not recommended." Not having such essential knowledge may delay the appropriate response warranted when suffering NSI. This will increase the risk of getting infected and so more education is needed regarding this issue.[7]

To conclude, the NSI prevalence was relatively low but there were many deficient area such as checking the immune status of the HCW against HBV, knowledge about the importance and methods of PEP, the crucial role of wearing gloves during handling needles, and reporting injuries when they happen.

\section{References}

[1.] Cullen, B.L., et al., Potential for reported needlestick injury prevention among healthcare workers through safety device usage and improvement of guideline adherence: expert panel assessment. J Hosp Infect, 2006. 63(4): p. 445-51.

[2.] Departments, U.K.H., Guidelines on postexposure prophylaxis for healthcare workers occupationally exposed to HIV. 1997, Department of Health: London. p. 1-42. 
[3.] Desalegn, Z., Gebreselassie S, and. Asemamaw Y, Epidemiology of Needle Stick-Sharp Injuries (NSSIs) and Potential High Risk Exposures among Health Professionals in Ethiopia: Neglected Public Health Concern American Journal of Health Research, 2015. 3(5): p. 298-304.

[4.] Gurubacharya, D. Mathura K, and. Karki D, Knowledge, attitude and practices among health care workers on needle-stick injuries. Kathmandu Univ Med J (KUMJ), 2003. 1(2): p. 91-94.

[5.] Hauri, A.M., Armstrong G.L, and. Hutin Y.J, The global burden of disease attributable to contaminated injections given in health care settings. Int J STD AIDS, 2004. 15(1): p. 7-16.

[6.] Ibekwe, R. and. Adam V, Injection safety practices among resident doctors in a tertiary health facility in Benin City. Nigerian journal of clinical practice, 2014. 17(4): p. 403-406.

[7.] Kermode, M., et al., Occupational exposure to blood and risk of bloodborne virus infection among health care workers in rural north Indian health care settings. Am J Infect Control, 2005. 33(1): p. 3441.

[8.] Muralidhar, S., et al., Needle stick injuries among health care workers in a tertiary care hospital of India. Indian Journal of Medical Research, 2010. 131(3): p. 405.

[9.] Osman, T., Epidemiology of sharp instruments injuries at a dental school in Sudan. International Journal of Infection Control, 2014. 10(4).

[10.] Pruss-Ustun, A.,. Rapiti E, and. Hutin Y, Global burden of disease from sharps injuries to healthcare workers. Geneva, Switzerland: WHO, 2003.

[11.] Sari, S.Y.I., et al., Knowledge, attitude and perceived adherence with universal precautions among health care workers in the obstetrics and gynaecology department of an Indonesian teaching hospital. International Journal of Infection Control, 2011. 7(4).

[12.] Sharma, S.,. Gupta A, and. Arora A, Knowledge, attitude and practices on needle-stick and sharps injuries in tertiary care cardiac hospital: a survey. Indian journal of medical sciences, 2010. 64(9): p. 396.

[13.] Updated U.S. Public Health Service Guidelines for the Management of Occupational Exposures to $\mathrm{HBV}, \mathrm{HCV}$, and HIV and Recommendations for Postexposure Prophylaxis. MMWR Recomm Rep, 2001. 50(Rr-11): p. 1-52.

[14.] (WHO), W.H.O., Standard supplies list. Universal Precautions, including Injection Safety. 2005. 